\title{
Trabajo, políticas sociales y sujetos "merecedores" de la asistencia: acuerdos y debates en el nuevo contexto neoliberal en Argentina
}

Labor, social policies and "deserving" subjects of assistance: agreements and debates in Argentina's new neoliberal environment

\section{Malena Victoria Hopp Doctora en Ciencias Sociales, Magíster en Políticas Sociales y Especialista en Planificación y Gestión de Políticas Sociales. Investigadora del CONICET en el Instituto de Investigaciones \\ "Gino Germani" (UBA). \\ malenahopp@yahoo.com.ar}

\section{Eliana Lijterman}

Licenciada en Trabajo Social; Maestranda en Investigación en Ciencias Sociales y Doctoranda en Ciencias Sociales (UBA). Becaria Doctoral de CONICET en el Instituto de Investigaciones "Gino Germani". eliana.lijterman@gmail.com
Fecha de recepción:

21.2.18

Fecha de aceptación:

16.5.18

\section{Resumen}

El objetivo del artículo es analizar la construcción social del merecimiento de transferencias monetarias del Estado Nacional argentino. Mediante la realización de grupos focales con distintas categorías de trabajadores/as reconstruimos las miradas, justificaciones y controversias recreadas sobre la asistencia, los sujetos destinatarios y su relación con el trabajo. Los discursos relevados ofrecen perspectivas de las condiciones y atributos morales para "merecer" de forma legítima la ayuda estatal. En ellos los asistidos son definidos como un "otro" moralmente diferente y los "planes sociales" son cuestionados. El análisis realizado muestra que los requisitos y atributos exigidos a los sujetos "dependientes" de asistencia constituyen un objeto de disputa que excede los requisitos formales-institucionales. Estas polémicas remiten a los alcances y contenidos de la integración social y del reconocimiento de los grupos excluidos de los parámetros de valoración social, principalmente, del trabajo asalariado. 
Palabras clave: política social - trabajo - asistencia social - transferencias monetarias - integración social - Argentina.

\begin{abstract}
In this paper we discuss the social construction of the "deservingness" of cash transfers in Argentina through to focus groups of different categories of workers to analyze the perspectives, the justifications and controversies about social assistance, its beneficiaries, and the relation with labor. Their discourses bring about perspectives on the conditions and moral attributes to legitimately "deserve" public aid: assisted people are defined as morally different and social help is questioned. Our findings reveal that the requirements and moral attributes demanded to the subjects "dependent" on social assistance constitute a field of dispute and controversy that exceeds the formal and institutional access requirements. We conclude that these controversies are about the scope and contents of the social integration and the recognition of the groups excluded from social valuation parameters, mainly, of wage labor.
\end{abstract}

Key-words: social policy - labour - social assistance - cash transfers - social integration - Argentina.

\title{
Introducción
}

El artículo que aquí presentamos se inscribe en el trabajo de investigación del Grupo de Estudios sobre Política Social y Condiciones de Trabajo, radicado en el Instituto de Investigaciones "Gino Germani" de la Facultad de Ciencias Sociales de la UBA. ${ }^{1}$ Dicha labor colectiva se articuló con base en un par de conceptos claves en la comprensión políticocultural de las políticas sociales: la autovalía y la dependencia legítima. Estos refieren a que la obligación de trabajar y el derecho a depender legítimamente del trabajo social y/o de otros se constituyen como configuraciones socio-políticas en los procesos de problematización e institucionalización de políticas sociales. La autovalía no se deriva únicamente del trabajo ni de las condiciones en que es realizado, sino de un complejo entramado político-institucional y cultural que sostiene la existencia de los individuos y hace posible (o limita) el desarrollo de las capacidades, los talentos y los méritos propios, que son siempre potenciales. 
Sin embargo, los soportes político-institucionales que moldean de manera fundamental la vida social e individual suelen ser naturalizados e invisibilizados. Por esta razón, nuestra investigación se pregunta por los modos de reconocimiento, desconocimiento y valoración de los mismos en la sociedad. En esta línea, hemos indagado los significados atribuidos a la autovalía y la dependencia a nivel institucional, en la discusión pública y por parte de diversos grupos socio-ocupacionales. Para ello, consideramos las necesidades reconocidas, la trama de recursos y los soportes político-institucionales para la satisfacción de las mismas presentes en las relaciones cotidianas de dichos grupos, así como las valoraciones sobre estos dispositivos para la vida propia y de otros. Nos propusimos dilucidar las justificaciones y fundamentos morales y normativos acerca de los desiguales recursos que disponen diferentes sectores sociales.

Para el trabajo de campo fue crucial una serie de grupos focales o de discusión, pues este dispositivo nos permitió acceder a perspectivas colectivas sobre estos temas, a los consensos y los debates surgidos en la interacción entre sujetos pertenecientes a distintas categorías socio-ocupacionales. La indagación cobró especial relevancia en tanto el trabajo de campo fue desarrollado en una coyuntura particular en Argentina: el primer año de gobierno de la alianza Cambiemos, iniciado en diciembre de 2015, con el cual se cerró el ciclo político de administraciones kirchneristas. En este nuevo contexto se evidenció una reorientación de las intervenciones sociales del Estado, movimiento que generó una intensa polémica pública cuyas marcas es posible rastrear en nuestros grupos de discusión.

En este artículo nos proponemos presentar algunas reflexiones sostenidas en el análisis de los mencionados grupos de discusión, sobre una cuestión en particular: la construcción social del merecimiento de las transferencias monetarias y la relación establecida con el trabajo. El merecimiento constituyó un capítulo central en el tratamiento de la cuestión de las políticas sociales en los grupos y, particularmente, de las transferencias monetarias (en palabras nativas, los "planes sociales"). En estos debates, la valoración de "los planes" se conectaba estrechamente con las formas de merecimiento percibidas como justas para ser destinatario de la acción estatal. Allí también se ponían en juego diferentes modos de valorar social y moralmente a los sujetos asistidos. Examinar los discursos sociales que conforman el sentido común acerca de los principios que sostienen o critican los regímenes de política social y dan fundamento a distintos modelos de Estado resulta de especial relevancia en la actual coyuntura de intensa transformación de los mismos.

La presentación de los resultados se organizará del siguiente modo. Primero analizaremos la relación entre merecimiento y trabajo en la asistencia social. Partiendo de esta conceptualización, presentaremos un breve recorrido histórico sobre la distinción entre asistencia y seguridad social en Argentina, que nos ayudará a comprender los sentidos y la centralidad que adquiere el trabajo como contexto de referencia de los debates sobre el merecimiento de las intervenciones sociales del Estado que se desplegaron en 
los grupos focales. En este orden, reponemos la relación establecida entre las interpretaciones sobre las situaciones de "no trabajo", los modos de distinción entre trabajadores y sujetos asistidos a las que ellas dan lugar y el cuestionamiento de los "planes sociales" como respuesta a estar problemática. El último apartado presenta las conclusiones, a partir de la síntesis y reconstrucción analítica de las miradas, justificaciones y controversias que encontramos en los diferentes grupos de discusión.

\section{Políticas y sociabilidades: la cuestión del merecimiento en la asistencia social y su relación con el trabajo}

La vinculación teórica entre la política social y el mundo del trabajo operó sobre una oposición construida históricamente entre el registro de la reproducción y el de la producción. El proceso de constitución de un mercado y una civilización "del trabajo" ha implicado la construcción de una barrera entre el fenómeno de la pobreza y el trabajo asalariado, hasta llegar a oponerlos simbólica e institucionalmente (Morell 2002). Esta oposición resulta constitutiva de la definición de las formas de integración social o de "utilidad en el mundo" (Castel 1997), procesos en los que las políticas sociales son protagonistas.

Entendemos la política social como la forma política de la cuestión social, en tanto no solo produce y moldea las condiciones de vida, sino que fundamentalmente reconoce y define las necesidades sociales y contribuye a constituir los sentidos del trabajo y de su sujeto, el trabajador, como parte de la producción de formas legítimas de pertenencia social en nuestras sociedades (Danani 2004). Es por ello que "cada modelo de política social, y cada política social 'real', son portadores de una pauta de sociabilidad políticamente constituida (y constituyente), que conlleva un proyecto de sociedad" (Danani 2017:81). Las políticas sociales construyen sociedad y son, al mismo tiempo, expresión de la misma.

En este sentido, se torna analíticamente significativa la diferenciación histórica, al interior de la política social, entre la seguridad social y la asistencia. Siguiendo a Castel, podemos caracterizar las prácticas asistenciales por dos factores: la proximidad entre el destinatario de la ayuda social y quien lo asiste, siendo "en la medida de lo posible, un analogon de la sociabilidad primaria” (1997:62), destinada a aquellas personas en riesgo de desafiliación social. El segundo elemento, es la ineptitud para el trabajo. La condición de pobreza, e incluso la de indigencia, no es suficiente para ser considerado sujeto de la asistencia: la legitimidad de la ayuda social (y de sus destinatarios) reside en las definiciones, históricamente variables, de la incapacidad de trabajar. La asociación entre la incapacidad para el trabajo y la inserción en la comunidad moviliza la distinción entre "buenos" y "malos" pobres, o pobres "merecedores" y no "merecedores" de asistencia.

Es por ello que el merecimiento refiere a una condición distintiva constituida como una exigencia moral que, en el campo de la política social, se despliega sobre el sujeto 
destinatario de la misma. Castaño Zapata (2015) distingue tres dimensiones que estructuran el merecimiento: a) la dimensión sociológica, vinculada con determinadas situaciones fácticas de necesidad; b) la dimensión normológica, referida a aquellas regulaciones que institucionalizan la intervención estatal sobre dichas situaciones; y c) la dikeológica, asociada a los valores compartidos, al ideal de justicia social que subyace a las mismas. El merecimiento a la asistencia se sustenta, entonces, en "razones" en estrecha conexión con juicios de valor con pretensión de universalidad. Los contenidos de la condición de merecimiento, que legitiman (o cuestionan) las intervenciones sociales y sus destinatarios, se construyen tanto a partir de un registro institucional que define las condiciones y requisitos formales de acceso a un derecho o prestación, como de un registro no institucional -social, cultural y subjetivo-, vinculado a las representaciones sociales y principios de justicia. ${ }^{2}$ Como argumenta el autor, ser "merecedor" es más que ser "elegible" por reunir características dispuestas normativamente, pues se trata de una cualificación moral. Por eso es que los debates y consensos sobre el merecimiento refieren no solo a la configuración de derechos y obligaciones, sino también a las dinámicas del reconocimiento social y la sociabilidad.

Los criterios de merecimiento que subyacen a un determinado régimen de política social no necesariamente se corresponden con los contenidos de los marcos valorativos sociales. Estos pueden adherir a ellas, o bien someterlas a crítica. En este artículo nos centraremos en analizar los fundamentos que se esgrimen en este registro no institucional acerca de las condiciones y atributos que deben reunir las transferencias de ingresos y sus sujetos destinarios para devenir legítimos. Intentaremos aportar a la comprensión de la construcción social del merecimiento a partir del análisis de los sentidos que dan diferentes grupos de trabajadores a formas de intervención estatal existentes o ideales y a las poblaciones que requieren de asistencia, y de las polémicas que se plantean a partir de las experiencias y prácticas de aquellos que son designados como tales. Así como Castaño Zapata señala que el merecimiento no constituye una categoría de contenidos "esenciales" sino de significaciones específicas, nuestro trabajo muestra que las características morales exigidas a los sujetos "dependientes" constituyen un objeto de disputa y controversia. ${ }^{3}$ Esta polémica remite, en suma, a las expectativas sobre los alcances y contenidos de la integración social y del reconocimiento hacia los grupos excluidos de los parámetros de valoración social, principalmente, del trabajo asalariado.

\section{Asistencia y Seguridad Social en Argentina: un breve recorrido histórico}

La oposición entre trabajo y pobreza ha sustentado un esquema de clasificación y de organización institucional entre asistencia a los pobres y seguridad social a los trabajadores, cuya construcción histórica es posible rastrear en nuestro país. Los análisis históricos sobre la política social en Argentina coinciden en señalar la diferenciación y relación 
complementaria entre asistencia y seguridad social (Grassi, Hintze y Neufeld 1994; Soldano y Andrenacci 2005; Danani y Hintze 2011).

Al menos hasta la década de 1980 los derechos sociales se expandieron a partir de la amplitud que adquirió la categoría de "trabajador asalariado", sobre la cual se construyeron seguros sociales corporativos de amplia cobertura, aunque segmentada. La asistencia, en cambio, se ocupó de quienes quedaron en "los márgenes" del empleo, el vector central de integración social (Soldano y Andrenacci 2005). La pobreza se asoció al estigma de la desocupación aunque, en esta dualidad, la integración productiva, social, cultural de los "marginados" constituyó el horizonte de sentido de las intervenciones asistenciales (Grassi, Hintze y Neufeld 1994).

Desde entonces, la política social delimitó un campo de intensa transformación en el proceso de consolidación de la experiencia neoliberal en el país, pues la misma se caracterizó por "su fervor desocializador del trabajo y del bienestar" (Danani 2017: 82). No solo se reconfiguraron las condiciones de vida, las políticas y las instituciones, sino las grillas de inteligibilidad de la vida social, la definición de los sujetos sociales y las formas de sociabilidad. En ese sentido el neoliberalismo debe ser comprendido en su capacidad de producción de formas de vida, de modos de existencia social que exceden la doctrina ideológica o la imposición de una política económica “desde arriba” (Danani y Grassi 2008; Dardot y Laval 2013; Gago 2015). La connotación negativa que asumieron las ideas de protección y seguridad en nuestro país, condujeron a un proceso sin precedentes de individuación y mercantilización de los seguros sociales. La seguridad social perdía su sentido y capacidad protectora, así como su soporte material: el pleno empleo. El correlato de este proceso fue el establecimiento de una estructura dual de bienestar: un mercado de seguros para los trabajadores asalariados formales, y el recurso de la asistencia pública para quienes se encontraran por fuera del mismo (Danani y Lindenboim 2003).

La nueva estrategia reforzó su contenido asistencial al dirigirse a una categoría de sujetos "vulnerables", escindidos de la esfera de la producción, así como se disoció la pobreza de las causas del empobrecimiento (Grassi, 2004; Merklen 2005). La exclusión social pasó a entenderse como un resultado previsible de la dinámica del mercado (Grassi 2003). Se produjo, entonces, una transformación del lugar residual que la asistencia social había ocupado hasta entonces, pasando a cobrar centralidad en el campo de las políticas sociales, en tanto el desempleo y la precariedad laboral pasaron a constituir los problemas centrales en los que se expresó la cuestión social.

La crisis económica, social y política de diciembre de 2001 marcó un resquebrajamiento de la hegemonía neoliberal y el cierre de un ciclo político. A partir de la caída del régimen de convertibilidad, y más fuertemente desde el año 2003, comenzó un proceso de transformación de las políticas económicas, laborales y sociales que contrastó con el 
carácter de aquellas del ciclo precedente. El nuevo modelo de Estado se fundamentó -y disputó su legitimidad- en la afirmación de la compatibilidad entre un crecimiento económico "genuino" (basado en el sector productivo y no en la especulación financiera) y la inclusión social, entendida como la integración a partir del trabajo formal, regular y protegido. Por ello, la seguridad social asumió centralidad en el patrón de intervención, lo que movilizó una serie de "contra-reformas" que pretendieron restablecer el carácter público y solidario del sistema y ampliar fuertemente la cobertura.

Tres transformaciones fueron relevantes en este movimiento de contra-reforma: a) la reinterpretación del principio contributivo, como en el caso de la moratoria previsional, a fin de incluir en los sistemas de seguridad social a trabajadores no registrados y desocupados; b) la relevancia asignada a componentes no contributivos para alcanzar a dicho conjunto de trabajadores; c) y el fortalecimiento de las prestaciones de las escalas inferiores de haberes. ${ }^{4}$ Una de las políticas más novedosas del período fue la institución del reconocimiento del derecho a las asignaciones familiares para trabajadores desocupados, informales, por temporada, del servicio doméstico y monotributistas sociales, mediante la creación de la Asignación Universal por Hijo en 2009 (Decreto 1602/2009). ${ }^{5}$ El alcance de estas medidas fue muy amplio y marcó un quiebre en la Seguridad Social argentina, ligada históricamente a la protección de trabajadores asalariados formales: más de 3,7 millones de nuevos jubilados por la Moratoria Previsional y 3,3 millones de niños, cubiertos por la Asignación Universal por Hijo (ANSES 2015).

La definición del trabajo como eje de la integración social en el discurso oficial condujo a que, desde la órbita del Ministerio de Desarrollo Social de la Nación (MDS), se optara por la instrumentación de programas de generación y fortalecimiento del trabajo asociativo y cooperativo para grupos en situación de vulnerabilidad, pobreza y/o desocupación (Hintze, 2007; Grassi, 2012) ${ }^{6}$ Concretamente, las cooperativas se dirigieron a la realización de obras públicas de baja complejidad y otras tareas de mejoramiento barrial y comunitario. Estos programas intentaron distinguirse de los planes asistenciales de la década anterior, por un lado, a partir de concebir el ingreso que brindaban a los destinatarios como una retribución por el trabajo realizado en cooperativas. Por otro, mediante la búsqueda del fortalecimiento de nuevas organizaciones de trabajadores, como parte de una direccionalidad política e institucional hacia la conformación de espacios colectivos de trabajo y capacitación orientados por los valores de solidaridad, inclusión y compromiso con la comunidad (Hopp 2017a).

La elección de Mauricio Macri a la Presidencia de la Nación, en diciembre de 2015, señala un quiebre en la orientación general de las políticas públicas, poniendo en el centro la reducción del déficit fiscal. El nuevo discurso oficial se sostiene en una confrontación directa con los sentidos que guiaron las políticas del ciclo previo. La profunda transformación de la política económica incluyó una fuerte devaluación de la moneda, apertura 
económica, eliminación de retenciones a la exportación de productos agrícolas, quita de subsidios a servicios públicos, entre otras medidas que favorecieron a los sectores agroexportador, financiero y a empresas de capital concentrado en desmedro de las PyMES y la industria local. Todo ello en un contexto de creciente inflación, acompañado del aumento del desempleo y la pérdida de poder adquisitivo de los salarios (CESO 2016).

El campo de las políticas sociales también experimentó transformaciones. En el marco de una relativa continuidad de las transferencias monetarias inscriptas en los campos asistencial y de la seguridad social, se produjeron algunas alteraciones en los sentidos de las políticas y en la definición de su sujeto de referencia. ${ }^{7}$ Una de las más relevantes tiene que ver con el cierre de la Moratoria Previsional y su reemplazo por una Pensión Universal para el Adulto Mayor de carácter no contributivo; ${ }^{8}$ se estableció así un régimen diferenciado para los sujetos sin la cantidad de aportes suficientes para obtener una jubilación ordinaria, a diferencia del reconocimiento que realizaba la moratoria del trabajo realizado en condición de informalidad. Recientemente, la aprobación de una reforma previsional en el marco de una intensa conflictividad social alteró la fórmula de movilidad de los beneficios, lo que junto a lo anterior señala un nuevo proceso de transformación del sistema.

En el caso de los programas del Ministerio de Desarrollo Social mencionados, se realizaron modificaciones normativas enfatizando la formación laboral y el fortalecimiento de la empleabilidad de los destinatarios (Res. MDS 456/16, 592/16 y 2055/16), que desplazaron la relevancia asignada al trabajo asociativo y a la figura de las cooperativas como forma de organización del mismo. En diciembre de 2016 se sancionó la Ley 27.345 que prorroga la Emergencia Social hasta el año 2019 y explicita la paulatina reestructuración de los programas sociales existentes y la transferencia de recursos hacia la instrumentación de un Salario Social Complementario, destinado a los trabajadores/as de la economía popular inscriptos en un Registro creado por la misma Ley. Finalmente, en febrero de 2018 se eliminaron los Programas "Argentina Trabaja" y "Ellas Hacen". Sus destinatarios fueron transferidos a "Hacemos Futuro", la nueva línea de política social creada en la órbita de la Secretaría de Economía Social, con el objetivo de "empoderar a las personas o poblaciones en riesgo o situación de vulnerabilidad social" y fomentar su "progresiva autonomía económica a través de la terminalidad educativa y cursos y prácticas de formación integral que potencien sus posibilidades de inserción laboral e integración social” (Res. MDS 98/18).

Este breve recorrido señala la centralidad que adquirió la asistencia en el campo de la política social nacional desde fines del siglo XX, así como la progresiva masividad del alcance de las modalidades de transferencia de ingresos. En contraste, la definición de sus problemas, sujetos de referencia y objetivos se alteraron en sucesivos ciclos históricos y continúa haciéndolo hasta la actualidad. Ante estas reconfiguraciones interesa problematizar la relación entre los registros institucional y social por los que discurre la 
definición del merecimiento de la asistencia, a fin de reflexionar sobre las condiciones de legitimidad de las transformaciones en curso.

\section{Metodología}

Los grupos focales o de discusión constituyen una técnica orientada a construir una situación de interacción social bajo condiciones controladas para captar la visión de un grupo determinado respecto de una serie de cuestiones problemáticas propuestas por la coordinación. Lo característico de esta técnica es su trabajo con el habla, la recreación por parte del grupo constituido de una situación discursiva cuyo campo semántico viene determinado por el investigador. Esta herramienta permite captar las articulaciones entre el discurso social, el sentido común y la expresión individual, habilitando el análisis sobre una trama de discursos y prácticas, debates y controversias, que constituyen los temas propuestos. Es por ello que "el grupo actúa como una retícula que fija y ordena (...) el sentido social correspondiente al campo semántico [propuesto]” (Scribano y Fraire 2008:117).

Estas características de los grupos de discusión nos llevaron a incluir su realización en nuestro trabajo de campo. Buscábamos ahondar en los sentidos que construyen distintos grupos de trabajadores acerca del Estado y las políticas sociales, prestando especial atención a los fundamentos por los cuales determinadas intervenciones sociales devienen (o no) legítimas. Nos interesaba sumergirnos en los consensos y las controversias surgidas en cada grupo y en la serie compuesta por estos, acerca de los principios de justicia asociados a dichos fundamentos. En estas situaciones de discusión colectiva podríamos seguir la huella de las identificaciones de grupo, de las distinciones respecto de otros, y de las valoraciones sobre los miembros "dependientes" de la sociedad y las intervenciones estatales destinadas a ellos. A su vez, la técnica posibilitó captar estados de opinión pública y reacciones coyunturales, lo que se tornó especialmente interesante dada la particular situación del país al momento de su realización.

Los grupos fueron conformados de acuerdo a una segmentación por categorías ocupacionales. La hipótesis subyacente era que la inserción laboral tiene un peso preponderante en la determinación del lugar social de los sujetos, desde el que se conforman las representaciones y visiones del mundo, los modos y condiciones de vida. ${ }^{9}$ De este modo, fue elemental la construcción de las categorías que definieron nuestras "clases en el papel". Éstas se distribuyeron para la conformación de los grupos de discusión, procurando lograr un balance entre proximidad social y heterogeneidad en las inserciones ocupacionales concretas, residencia, género y edad..$^{10}$ Se realizaron dos sesiones de discusión para cada uno de los siguientes grupos, durante los meses de septiembre y octubre de 2016 en las instalaciones de la Facultad de Ciencias Sociales y en el Instituto de Investigaciones "Gino Germani” de la Universidad de Buenos Aires: ${ }^{11}$ 
- Obreros/as formales y trabajadores/as autónomos/as informales.

- Trabajadores/as del servicio doméstico (registrados/as o no) y trabajadores/as autónomos no registrados.

- Trabajadores/as rutinarios/as de los sectores público y privado. Comprende a quienes se desempeñan en tareas eminentemente administrativas.

- Profesionales con formación universitaria, con un ejercicio liberal-autónomo.

- Cooperativistas: asociados/as a cooperativas de trabajo y pertenecientes a cooperativas creadas por los Programas Ingreso Social con Trabajo "Argentina Trabaja" y "Ellas Hacen". ${ }^{2}$

En cuanto al análisis, en una primera instancia realizamos una lectura "horizontal" de las sesiones de discusión, buscando identificar temas comunes, términos en los que se expresaban los problemas identificados, los modos en que entendían que esas cuestiones sociales debían ser abordadas, y sus experiencias y vínculos con el Estado y las políticas sociales. Luego, profundizamos en la distinción de las visiones compartidas y las controversias en cada grupo focal, entre distintas sesiones de iguales categorías ocupacionales, y de manera transversal. Asimismo, distinguimos los temas emergentes de aquellos planteados por la coordinadora. Progresivamente, fuimos construyendo categorías que nos permitieran comprender los sentidos del trabajo y de la política social, y los fundamentos y principios de justicia que organizaban los debates en torno a distintas formas de intervención estatal.

La cuestión de los "planes sociales", el trabajo y el "merecimiento" de la asistencia social que analizaremos, fue uno de los temas que tuvo una presencia transversal y generó intensos debates en todas las categorías ocupacionales. En este artículo, tomaremos los grupos focales realizados con trabajadores/as rutinarios del sector público y privado, los/as cooperativistas y destinatarios/as de los programas "Argentina Trabaja” y "Ellas Hacen" y los/as obreros/as y trabajadores/as informales. La selección de las mismas obedece a que son próximas en el espacio social, aunque también lo suficientemente diversas en cuanto a su experiencia con las políticas sociales, lo que nos permitió un ejercicio de contrastación para el análisis del material producido. 


\section{La centralidad del trabajo en la discusión sobre merecimientos y planes sociales ${ }^{13}$}

Los debates acerca de los merecimientos y la justicia de las políticas de transferencia de ingresos, así como sobre las características que éstas deberían asumir, encuentran en el trabajo un contexto de referencia central.

Identificamos algunos nudos de significado respecto del trabajo que atraviesan transversalmente a las distintas categorías ocupacionales con las que conformamos los grupos de discusión. Entre ellos, el sentido del trabajo como eje definitorio de la pertenencia a la sociedad: en virtud del aporte productivo al conjunto, en el trabajo se encontraría el núcleo de la valía de los sujetos. El trabajo construye a la sociedad, no solo porque crea la riqueza sino porque la organiza, articulando derechos y obligaciones, aportes y aspiraciones legítimas sobre qué dar y qué beneficios se van a percibir. El trabajo emerge como vector de subjetivación y soporte en la construcción de identidad y del proyecto de vida propio. Se plantea como fuente de reconocimiento de los otros y de la autovaloración. En ese sentido, hallamos múltiples referencias en los grupos de discusión al "aprendizaje" de los participantes, desde su hogar y a través de distintas generaciones, de la "cultura del trabajo" y "del esfuerzo" y de los valores morales asociados a ellos. ${ }^{14}$

Y: Estoy de acuerdo con que haya gente que necesita [programas sociales]... [Pero] más que el dinero, por ahí darles otro tipo de ayuda...(...) Necesita otros medios, ayudarlos a sembrar, es [Argentina] un país que tiras una semilla y crece. Hacer cosas, oficios también.

E: ¿Por qué te parece que eso es mejor ayuda que el dinero?

Y: Porque el país crece. Porque si vos producís en algún momento vas a tener que vender. A los mismos el país, si haces más, vas a tener que exportar. A mí me parece que crece el país, no con planes que la gente no hace nada.

(Obreros/as y trabajadores/as informales. Grupo 4)

Estos sentidos no son absolutos sino relacionales: se despliegan en diálogo y contraste con otros modos de ganarse la vida y de participación social. En algunos grupos focales, la vida anclada en el trabajo propio se reafirma en su valía distinguiéndose de los "planes sociales", como política de Estado y modo de vida de "otros". El sentido del trabajo como clivaje identitario, como fundamento de la solidaridad y de la integración 
a la sociedad, promueve una mirada de quien es asistido como un "otro" moralmente distinto, no adscripto a la cultura del esfuerzo y sostenido por la comunidad sin realizar aportes de ningún tipo. Siguiendo a Georg Simmel, Paugam (2007) plantea que lo que hace que una persona sea considerada pobre (y nada más que pobre), es precisamente, la ayuda que recibe públicamente. Cada sociedad define y confiere un estatus diferente a quienes otorga asistencia y en esa relación de interdependencia se construye la identidad, la valoración y las formas de reconocimiento de los sujetos y gruposasistidos.

E: Esto de la autovalía, ¿cómo ustedes, en el día a día, entienden su autovalía?

\section{G: Trabajando.}

A:Logrando.

L: Conservando el trabajo también. Hay mucha gente que falta por cualquier cosa. Yo he ido con fiebre a trabajar[...] Me parece que acá falta cultura de trabajo.

E: ¿Y qué es eso? La cultura del trabajo, porque muchos me mencionan esto.

L:Que la gente tome el trabajo como una responsabilidad. Como que vos vivís de tu trabajo y no pongas cualquier excusa para faltar.Yo tengo a mi hijo trabajando hace 3 años que aparte de estudiar trabaja.[...]El chico fue aprendiendo de los padres, primero obviamente escuchan, ven como es el movimiento en la casa y me dijo: 'mamá yo quiero trabajar y ganar mi propia plata'.

E: ¿Esta es la cultura del trabajo?

C: Ya de por sí la cultura, la educación es todo.

E: ¿Y eso de que depende?

L: De la casa.

C: De nosotros.

(Obreros/as y trabajadores/as informales. Grupo 11)

F: [discutiendo sobre alternativas a la existencia de "planes"] Hacer algo a cambio, no ir a aplaudir y el choripán ¿qué hiciste por la sociedad además de cobrarlo?”

(Trabajadores/as rutinarios/as. Grupo 2) 
A diferencia de esta red de sentidos sobre el trabajo, presente en los grupos de obreros y trabajadores informales y de empleados rutinarios, quienes vivieron en su propia experiencia las dificultades para conseguir un empleo o son titulares de un programa social, discuten la representación dominante que los estigmatiza y el mandato social que lleva al trabajo en cualquier condición (expresado en la valoración positiva de concurrir al trabajo, aun estando enfermo: "he ido con fiebre a trabajar"). ${ }^{15}$ Desde otro lugar social se problematiza la idea del trabajo como pura obligación que pesa sobre los sujetos considerados carecientes, vagos o incapaces, pero que en sí mismo no es objeto de ningún tipo de protección, reconocimiento o garantías.

Aquellos participantes que son destinatarios de programas sociales, acuerdan con la idea general del trabajo como vector central de la integración social. Ello se expresa justamente en una diferenciación fundamental entre el plan y el trabajo, asociada inmediatamente a la demanda de otra forma de intervención estatal que posibilite acceder a un trabajo genuino. Este acuerdo respecto de la incapacidad del plan para garantizar el reconocimiento no se fundamenta en la necesidad de que todos aporten por igual al crecimiento de la sociedad, sino en las desigualdades de clase, de acceso al mercado laboral y en el propio deseo de formar parte de ese mundo del trabajo para poder contar con la seguridad y los derechos que éste garantiza:

P: (destinataria del Programa Argentina Trabaja): A mí me gustaría que abran industrias, trabajar, hacer otra cosa, cumplir un horario... porque es solo una hora y media... yo quiero trabajar... un laburo de 6 horas, 8 horas, lo que sea(...). Lo que yo hago es trabajo insalubre, ¿me entendés? Por eso me gustaría estar dentro de la Municipalidad. Nosotros estamos barriendo la mierda de los perros, hay cloacas que salen a las calles... la mierda de la gente de las casas...y nosotros barremos eso.

D: ¿Pero no tenés el sueldo de barrendero común? Voces: ¡Nooo! Los del plan. Sin aguinaldo, sin nada. P: No. $\$ 3400$ pesos. ${ }^{16}$ Es un trabajo insalubre. [...] S: (destinataria de Ellas Hacen):Está perfecto, que eliminen los planes pero que generen trabajo, que abran industrias... Mi marido es aparador de calzado, de 30 aparadores del año pasado, ahora están quedando 10, los más antiguos, y no se les puede largar por largar nada más...entonces el patrón está haciendo malabares para tratar de cortar, quizá aunque no tenga pedidos para mantener a esos 10 antiguos... entonces uno está diciendo cómo sacarse esto pero 
no vemos un...no sé, para nosotros los que estamos muy abajo es como que todas las luces son prendidas para los que están arriba. La luz se ve desde arriba nada más, de abajo todo oscuridad. ${ }^{17}$

(Cooperativistas y destinatarios/as de Argentina Trabaja y Ellas Hacen. Grupo 9)

La centralidad del trabajo en la construcción de identidades resulta un eje insoslayable para comprender las demandas de reconocimiento, las retribuciones esperadas por el aporte productivo realizado a la sociedad y las distinciones frente a un otro social y moralmente distinto, asociado con el "no trabajo". Recurrimos a la idea de "no trabajo" para referirnos a diversas situaciones que se alejan del ideal de trabajo "normal" (Grassi y Danani 2008) y que, por ello, conforman un espacio ideal caracterizado por la inscripción de una falla o carencia. En su dimensión simbólica, el "no trabajo” se asocia con la pobreza y el desempleo y su efecto es el desconocimiento de otras modalidades de ocupación y de producción de valores de uso diferentes al trabajo asalariado (las changas, el autoempleo, el trabajo doméstico y de cuidado, las tareas que se realizan en el marco de programas sociales, etc.).

Los modos históricamente variables de identificar, explicar y dar sentido a las situaciones de "no trabajo" suponen construcciones y cualificaciones morales diversas en torno a los sujetos afectados. Asimismo, son un elemento clave para comprender el "deber ser" de las políticas sociales y la "justicia" o "injusticias" asignadas a las transferencias monetarias. Nos dedicamos a ello en lo que sigue.

\section{Trabajo y planes, trabajadores y asistidos: explicaciones del "no trabajo" y formas de reconocimiento}

Los sentidos del trabajo que relevamos entrañan formas de autopercepción sostenidas en la trayectoria laboral, propia y familiar, junto con una reiterada distinción respecto de los destinatarios de programas sociales de transferencias de ingresos.

La expresión utilizada en los grupos de discusión "vivir de planes", señala la idea de que estos delimitan formas de vida y opciones morales arraigadas. La permanencia en la situación de desempleo se explica, en ocasiones, por una pérdida intergeneracional de la cultura del trabajo, que condensa sus efectos negativos en los más jóvenes. Los argumentos que se esgrimen al respecto coinciden mayoritariamente con la percepción de la juventud como un grupo problemático, desligado de la "cultura del trabajo" y de la retórica meritocrática “del esfuerzo” (Chaves, Fuentes y Vecino, 2017). 
$\mathbf{N}$ : Hablando de gobierno... el gobierno anterior creó mucha gente ignorante con planes y con todas cosas que vos decías... 'tengo esta plata así'... '¿para qué voy a trabajar si tengo esta plata?'...Hoy en día, no quieren trabajar. Si un pibe hay que llamarlo... El otro día vino el pintor y me dice 'no... no tengo a nadie’. Porque no quieren trabajar. Por más que les paguen $\$ 200, \$ 300$ si es plata, vas a trabajar igual.

E: ¿Por qué no quieren trabajar?

N: Porque no, no. 'Por eso no trabajo'.Y se cansan, trabajan uno o dos días y están cansados.

E: Pero ¿y de qué viven?

P:Y...de planes la mayoría.

C: Algunos tienen planes.

E: ¿Viven de planes? (...)

R: Si ve al padre que está todo el día en la casa, el chico ve eso.

M: Sigue los pasos del padre.

$\mathbf{R}$ : Antes tu papá te decía 'o estudias o trabajas...'. No te quedaba otra.

(Obreros/as y trabajadores/as informales. Grupo 4)

Sin embargo, en la discusión emerge un contra-argumento que problematiza las condiciones sociales y laborales en las que esos jóvenes deben insertarse y crecer para formar parte y ser plenos miembros de la sociedad. La propia experiencia de ser destinatarias de programas sociales (y la de sus hijos en relación con ella) se pone en juego para cuestionar la visión dominante. Este es el caso de una de las destinatarias del Programa "Ellas Hacen":

E: Algo que escuchamos es esto de la cultura del trabajo. ¿Qué me dicen con respecto a esto?

C: (destinataria de Ellas Hacen): La juventud viene muy vaga... porque eso no se lo implanta desde la casa, la enseñanza empieza por casa. Está perdida la juventud...

D: Gente de menos de 30 años, intomable! [para un trabajo]. E: ¿Están de acuerdo con esto de que tiene mucho que ver con los padres? ¿O tiene que ver con otras cuestiones?

S: (destinataria de Ellas Hacen): ¿Qué se le ofrece a la juventud hoy en día? A alguien de 17 o 18?... lo fácil.Yo escuche que iban a eliminar todos los planes porque 
mantienen y fomentan vagos y ahora estamos llegando a diciembre y nos quieren tapar la boca con un bono de 1000 pesos, entonces...está perfecto, que eliminen los planes pero que generen trabajo, que abran industrias...

(Cooperativistas y destinatarios/as de Argentina Trabaja y Ellas Hacen. Grupo 9)

En cambio, en otro de los grupos la distancia social, pero fundamentalmente moral, moviliza el temor hacia el lugar social que la juventud encarna, hacia figuras percibidas como desenganchadas del mundo laboral, del estudio y, en términos más generales, de ciertas coordenadas normativas básicas que orientan la sociabilidad; y que por ello son comprendidas como pura alteridad que debe ser controlada.

W: Yo creo que si le das un plan les tienen que dar de pronto una capacitación. Mínimo. Capacitarlo para algo o enseñarle algo a la persona porque si le das el plan y no los obligas a nadase desperezan, se quedan tranquilitos y como en la vida cotidiana empiezan a buscar de hacer... como quien dice... hasta maldades y ahí empieza todo.

$\mathbf{N}$ : Que se vuelven vagos, sí.

W: Entonces tienen que tener una obligación, un chequeo, tienen que presentarse a algún lado, controlarlos.

(Obreros/as y trabajadores/as informales. Grupo 4)

F: Yo creo que si no tengo trabajo y lo busco y no lo encuentro y me dan plata el gobierno, lo acepto. Sigo buscando y no encuentro, bueno denme para hacer algo no sé, te limpio una plaza, te pinto, no me quedo en mi casa viendo la tele (...)

I: El hecho es ese, vos por ahí estás fuera un montón de horas, lejos de tu hijo, de tu pareja, de tu familia, (...) trabajé toda la semana y ver que por ahí otro cobra plata sin hacer absolutamente nada, y vos decís: 'yo me estoy esforzando, ¿para qué?'. (...) Si yo lo hago ¿por qué el resto no lo hace?

E: Y ahí una pregunta, (...) ¿acordáis por ejemplo con que el Estado no de más planes?

I: No, no, que dé los necesarios, que dé pero que controle y que devuelva algo a la comunidad. Pero no 
te exijo, que yo trabajo 8,10 horas, que no trabaje lo mismo que yo pero 2 o 4 , como dice ella, se perfeccionen y a su vez que trabajen.

(Obreros/as y trabajadores/as informales. Grupo 3)

Estos argumentos se asocian con un cuestionamiento hacia los "planes sociales" en virtud de sus efectos negativos, morales y sociales que reforzarían la descalificación, la pérdida de la cultura del esfuerzo y de la incapacidad de realizar un aporte valioso a la sociedad. La propuesta planteada respecto de asistir a quien lo necesita con la condición de brindarle "otros medios" para que pueda producir, remite a la idea liberal sobre el progreso material de la sociedad que se realiza a partir de la contribución de cada individuo a ella. Desde esta perspectiva, Schmidzt (2000) representa el funcionamiento de la sociedad como una marea intrínseca que hace subir a los barcos que toca y deja atrás al resto. Esta metáfora interpreta la sociedad a partir de un movimiento "natural" (el mercado) que empuja a quienes participan en él, pero deja atrás a aquellos que no lo hacen, ya sea porque son improductivos y no logran contribuir al progreso social o bien porque no pueden responsabilizarse por su propio bienestar o no son capaces de realizar algo valioso para el conjunto. Esta forma de comprender el funcionamiento social que desconoce e invisibiliza los soportes sociales e institucionales necesarios para ello, da fundamento al rechazo del "plan" como estrategia de intervención sobre las situaciones de desempleo o pobreza. Al mismo tiempo que coloca al sujeto destinatario de la intervención pública como una carga para la sociedad que debe sostenerlo, sea éste o no responsable de su situación.

Frente a la asociación de los "planes" con la vagancia y el desconocimiento de los destinatarios como miembros plenos y valiosos para la sociedad, quienes han participado de los programas sociales discuten la mirada que homogeneiza las distintas experiencias que se despliegan en el marco de las políticas, poniendo de manifiesto los logros personales y colectivos que esta forma de intervención estatal habilita. Esto se percibe sobre todo en los grupos de cooperativistas y destinatarios de "Argentina Trabaja" y "Ellas Hacen", en los que algunos participantes destacaron el esfuerzo por salir adelante y superar la situación en la que se encontraban previo al ingreso al programa:

S: Por eso duele cuando se escucha que todos los que reciben plan son vagos. Sabes lo que cuesta levantarse a las 5 de la mañana para llegar a la universidad a las 8.30, 9 porque tenés que viajar de González Catán, tomarte 3 colectivos y llegás a Constitución y se te cancela el tren que te llevaba a horario.[...] y también le digo a cualquiera que me encuentre, porque esta es nuestra oportunidad... es la oportunidad 
para relucirnos y hacer las cosas bien, para que los que tanto se llenan la boca diciendo que no servimos para nada o que somos vagos... hay que demostrar que de verdad hubo gente que utilizó ese tiempo para algo valioso $[\ldots]$.

L: [...] pero yo sí aproveché las oportunidades que me daban. Yo quiero estudiar gastronomía, hice curso de auxiliar de familia, de cuidador de persona. Aproveché todo ese tiempo de oportunidades.

(Cooperativistas y destinatarios/as de Programa “Argentina Trabaja y Ellas Hacen. Grupo 9)

El contrapunto está dado por otros casos en los que se cobra "sin hacer nada", sin dar algo a cambio:

M: Para "Argentina Trabaja" yo trabajo cuatro horas en el Municipio de Quilmes. Todos los días, de lunes a viernes. Hay gente que, por supuesto que hay grupos que no van, porque no hay un control en sí.Yo voy.Yo tengo una planilla que me firma el encargado de mantenimiento. Me la firma todos los viernes. Y yo presento la planilla en Empleo. Ahí mismo, en el edificio.Voy, la presento, tiene mi nombre y mi apellido, mi número de documento. Yo misma lo firmo porque nadie se encarga de mí. Mi grupo de cooperativa está dividido. Antes éramos un grupo que estábamos en el gobierno de Cristina, estábamos en una delegación. Después... digamos... El tema era trabajar. El tema era trabajar. No importaba dónde pero bueno... el tema era trabajar. [...] Siempre quise cambiar, dejar la cooperativa. Porque cuando me ofrecieron y entré me pintaron que era para trabajar en el barrio, que ibas a cobrar un sueldo, bueno... la obra social que tengo es la del sindicato de los empleados de comercio. Es muy buena. Es lo único bueno que rescato de la cooperativa. [...] no tengo recibo, no tengo aguinaldo.

(Cooperativistas y destinatarios/as de Programa “Argentina Trabaja y Ellas Hacen. Grupo 10) 
Para comprender esta mirada y las discusiones que plantean respecto de la política social, del trabajo y de los derechos asociados a la condición de trabajador/a, es importante contextualizar estos discursos en la experiencia de los programas de promoción de cooperativas implementados en el período 2003-2015 que describimos anteriormente, en particular por su objetivo de integración social a través del trabajo y el reconocimiento de derechos que impulsaron para trabajadores históricamente excluidos del sistema de seguridad social. Este marco de sentido que se intentó construir a partir de los valores, principios y prácticas de la Economía Social y el cooperativismo en espacios colectivos de trabajo, atraviesa los discursos y da fundamento a la distinción entre los planes definidos como aquellas experiencias en las que se cobra sin trabajar y los programas de capacitación, trabajo e inclusión social como "Ellas Hacen" en los que participan. Esta diferenciación es tanto un medio para discutir el valor social de estas iniciativas, cuya legitimidad es permanentemente puesta en cuestión, como una forma de evadir el estigma ante el desprestigio que afecta a sus protagonistas. Tras ella, la categoría de "planes" permanece en un registro negativo, asociada al "no trabajo" o a un trabajo devaluado en tanto fuente de derechos y reconocimiento social.

$\mathbf{N}$ : (socia de cooperativa gráfica): (...) Cultura del trabajo me hablás, ¿qué trabajo me hablás? Trabajo genuino.Yo lo que sí entiendo y respeto es la postura de mucha gente que dice, "bueno, planes sociales", sí, son planes, ¿están tirando la plata? No, yo conozco fehacientemente que laburan. (...) Pero este tipo de cooperativas, se tendría que haber profundizado. $\mathrm{O}$ sea, ser un laburo genuino. ¿Sí? Para mí tendría que haber sido el proyecto de que una empresa privada, más el dinero que da el Estado, entonces hacemos un sueldo, como quiere acá encarar la compañera. Pero no es trabajo genuino. No es trabajo, no lo hay.

(Cooperativistas y destinatarios de Argentina Trabaja y Ellas Hacen. Grupo 10)

Entre los argumentos de rechazo hacia los programas de transferencias estatales, emerge también un sentido espurio de la política, ligada exclusivamente a la búsqueda del interés personal y al clientelismo. A esta mirada, se contrapone una perspectiva que recoloca el foco del problema en la responsabilidad individual y colectiva por el uso que se hace de los recursos públicos y en la capacidad para aprovechar las oportunidades que se les ofrecen.

C: (Destinataria Ellas Hacen): Existen las dos partes [...] Están los que son arreglados políticos y los que realmente quieren trabajar. [...] que se rompen el alma 
por llevar el peso a su casa... a esos 8 no se los ven trabajar y ven al resto... que son unos vagos, entonces por eso está mal visto el programa.

R. (cooperativista): También tiene que ver mucho con esto de la política, la política te agarra y utiliza los planes para rosquear a sus propios punteros. $\mathrm{La}$ gran mayoría de gente que tiene deseo de trabajar no accede a los planes, porque cada uno de los punteros va metiendo a su familia.[...]

L: (Destinataria Ellas Hacen): El programa está espectacular, el tema es que nosotros como sociedad, como ciudadanos no queremos hacernos responsables de tener una empresa, porque eso es lo que es una cooperativa, y tomar las responsabilidades y las riendas de nuestra propia empresa.

(Cooperativistas y destinatarios/as de Argentina Trabaja y Ellas Hacen. Grupo 9)

De este modo se presentan dos lecturas alternativas del desempleo: una mirada moral e individual; y otra orientada a discutir el estigma de los titulares de programas sociales desde la experiencia de la desocupación. Entre estos dos "extremos" emergen otro tipo de argumentos que expresan la desigualdad de oportunidades en el acceso a la educación y a los puestos de trabajo. En este sentido, participantes de los distintos grupos se refieren a la discriminación simbólica hacia los sujetos que habitan en "villas de emergencia" u otras zonas desprestigiadas en entrevistas laborales. Las "zonas marginales" se vuelven en estas explicaciones "zonas marginadas" por el propio abandono estatal y la segregación respecto de los servicios públicos, en la que el deterioro de la educación cobra un peso determinante. Estas interpretaciones dan cuenta de que las "opciones personales" dependen, en realidad, de una estructura de oportunidades y de esos soportes sociales e institucionales invisibilizados y desigualmente distribuidos.

A: Por supuesto...Hay una vulnerabilidad increíble y no hablo de gente que vive al margen de la ley ni mucho menos, que sea marginal. A veces la marginalidad proviene de los gobiernos, de las politicas sociales y económicas que empujan a la marginalidad.

(Obreros/as y trabajadores/as informales. Grupo 3) 
En otros momentos del debate, el desempleo emergió en su relación con las formas de crecimiento o desarrollo económico seguido por el país, estableciéndose una relación con la coyuntura en la que se realizaron las sesiones grupales. Las coordenadas macroeconómicas que asumen los gobiernos constituyen modelos productivos con capacidad de crear o destruir puestos de trabajo, incidiendo en las condiciones de vida. Por ejemplo, se advirtieron los efectos negativos de la creciente inflación y del incremento extraordinario de las tarifas de los servicios públicos en el desempeño de las pequeñas y medianas empresas. En este sentido, algunos/as participantes visualizan que sus propias inserciones dependen de las políticas estatales para fomentar ciertos sectores de actividad privada.

E: Algo concreto. Dame un caso concreto. ¿Hay algo hoy que te está prestando el Estado?

S: (trabajadora en una empresa de cosméticos): Me da la posibilidad para poder trabajar y me da el dinero que necesito para vivir. (...)

E: ¿Cómo es que te lo presta, cómo te lo da?

S: Yo cumplo con mi trabajo, el Estado es el que me da la oportunidad de poder trabajar. (...) Me da la posibilidad de que la empresa pueda producir.

E: ¿Y por qué el Estado le da esa posibilidad a esa empresa?

S: Ellos nos hacen entender, los dueños, que tenemos ayuda.

E: Los demás (...) ¿Dependemos en algo del Estado?

D: (trabajador en una fábrica de envasado): De las decisiones que toman. [...]

G: (trabajadora en una fábrica): Si el Estado me sube el doble a todo lo que estoy pagando entonces dependo porque ya no puedo pagarlo.

(Obreros/asy trabajadores/as informales. Grupo 3)

I: (trabajadora en cooperativa metalúrgica): A nosotros, por lo menos a nuestra cooperativa, el gobierno de Macri nos arruinó. Porque la luz, de estar pagando 42.000 pesos por mes, más o menos, ahora estamos en los 260.000 mensuales. Que eso, de todas las ganancias que uno va formando para tener un capital, lo tuvimos que ir sacando. Sacamos de esos capitales que la cooperativa tenía para, en vez de poder invertirlos, tener que pagar los servicios. [...] 
E: Los demás, ¿̇en qué cosas se van fijando a la hora de medir cómo un Estado, en los niveles que sea, contribuye o no a nuestro mantenimiento, a nuestro bienestar? ¿En qué cosas ponemos el foco? L: (trabajadora en cooperativa gráfica): En este momento estamos en un momento de ajuste total. O sea, las cooperativas la están pasando súper mal. Y las [empresas] recuperadas, también. [...]

A: (trabajador en cooperativa de producción de pintura): Está complicado. Nosotros tenemos parada una máquina y no la pensamos poner en marcha por el incremento de gas. Sumado a la recesión. Es imposible. Es más, estamos considerando traer cosas de afuera y no fabricar.

L: (trabajadora en cooperativa gráfica): Nos complica también en armar presupuestos. Todos los días cambian las cosas.

(Cooperativistas y destinatarios/as Argentina Trabaja y Ellas Hacen. Grupo 10)

Estos diversos argumentos ponen de relieve la situación de carencia, necesidad o las dificultades que atraviesan miembros de la sociedad, inscribiéndolas en un registro que no es puramente individual. Ello moviliza el reconocimiento de la pertinencia de una acción de ayuda e intervención por parte del Estado que matiza el cuestionamiento radical hacia "los planes", ampliando también los sentidos asociados a la política social y dando lugar al reconocimiento de soportes institucionales para el sostenimiento del trabajo.

O: Catamarca es [una provincia argentina] muy sencilla y más de la mitad tiene el plan social y son gente buenísima. No hay trabajo, si no hay industria, no hay trabajo, no hay billete, panza, la comidita... No hablemos más de nada ni de la gente, porque no hay trabajo. Es más, lo poco que había (...) se inventaron en España cosechadoras que un tipo con una máquina,ya no necesitás a la gente para cosechar (...).Y esa gente ¿el Estado qué hace? ¿Qué se mueran? ¿Qué se maten?, decir que son pocos habitantes en Catamarca. Y los planes sociales, como decís vos, son mil pesos y la vida igual o más cara que acá, lo único barato es el membrillo, dirían las viejitas del barrio, pero la vida vale igual... me parece muy bien.

(Trabajadores/as Rutinarios/as. Grupo 2) 
Finalmente, resta destacar que esta diversidad de argumentos por lo general no dio lugar a la emergencia de una controversia expresa, pese a que estos puedan pensarse, a priori, como mutuamente excluyentes: los argumentos de matriz moral e individual acerca del desempleo conviven con otros que advierten factores de responsabilidad colectiva y, en ocasiones, se producen modos de ensamblaje entre estos. Un ejemplo de estos ensamblajes complejos es la distinción que muchos participantes realizaron entre "programas" y "becas", destinados al trabajo y la formación, valorados positivamente, de "los planes" a los que se asocia un estigma.

Fueron pocos los momentos en que en los grupos se conformó un diálogo polémico a partir del cuestionamiento al argumento moral e individual sobre el desempleo, que se presentaba de forma sólida y reiterada. Los cuestionamientos directos visibilizaban el carácter ideológico de estas lecturas, haciendo aparecer -por debajo de éstas- múltiples formas de desigualdad, distinción y estigmatización:

D: ¿Puedo hacer una pregunta? Yo, gracias a dios, trabajo y no me tocó cobrar un plan pero quiero saber cuánto es un plan, porque capaz que cobrás dos mil pesos y una familia no vive con dos mil pesos... Incluso con el tema de la Asignación Universal por Hijo... la cantidad de cosas que escucho decir... 'tienen hijos los negros para poder cobrar el plan'... ¿De verdad pasa eso? Porque si pasa, eso a mí me sorprende. Tener un hijo para poder cobrar dos mil pesos por mes me parece irreal. Creo que es una ayuda para todas las familias humildes. Creo que hay oportunismo que dicen que si pueden cobrarlo, lo cobran pero no creo que vivamos con eso realmente y que puedan vivir por mes. Considero que hay algo más de eso.

E: ¿Qué es ese algo más?

D: Que cada uno se las arregla de otra manera. No creo que con dos mil... no sé cuánto es una asignación y cuánto es un plan pero con respecto a distintos tipos de planes como Procrear... yo creo que eso ayuda a muchísima gente (...). No hago política pero si estaba con el gobierno anterior porque si tenía la integración social. (...) Te doy un ejemplo. Hay gente que tiene mucha plata y no está de acuerdo en compartir unas vacaciones en Cuba con un negro villero y el "negro villero" hace dos años se podía ir a... Negro villero estoy diciendo entre comillas (...). Las familias ricas les llaman negros villeros, que somos los trabajadores 
en realidad, para ellos nosotros somos esa clase de persona y nosotros estamos ahí o cualquier persona trabajadora en un lugar a donde antiguamente acostumbraba a ir solo la clase alta y para ellos es chocante.Yo creo que lo que hizo el gobierno anterior es tratar de achicar la brecha entre los más ricos y los más pobres, que los más pobres tengan un poquito más.

(Obreros/as y trabajadores/as informales. Grupo 11)

S: (trabajadora cooperativa gráfica - audiovisual): El resentimiento de la clase media, que pudo acceder a un montón de cosas que la clase baja no pudo, o no puede.Y entonces no les deja ver la necesidad de ciertos planes y programas que se necesitan, orientados a estas clases más vulnerables. Desde ese punto de vista, el punto de vista de la clase media, trabajadora, se ve como que la plata les cae del cielo de pronto. No llegan a ver el porqué de la necesidad.

$\mathbf{N}$ : (destinataria Ellas Hacen): Y de repente tampoco saben el laburo que hace, ponele, yo te digo Argentina Trabaja.[...] Para empezar, estamos diciendo que estas prestaciones, los planes, lo que sea... Había que salir con eso porque no hay un mango. Si hoy no alcanza, y estamos hablando de Argentina Trabaja y de otros programas, 3.400 pesos, ¿no es cierto? Calculá...O sea, antes le podías comprar la zapatillita, un montón de cosas antes.

Voces: Podíamos ir al cine antes. (Risas).

$\mathbf{N}$ : (destinataria Ellas Hacen): ¿Era un pecado, o sea, acceder a beneficios de clase media? Ir al cine, poder comprar zapatillitas, llevarlos al cine, por ejemplo. Un montón de cosas que hoy por hoy no se pueden hacer.

(Cooperativistas y destinatarios/as Argentina Trabaja y Ellas Hacen. Grupo 10)

\section{Planes no, empleo. Las alternativas más allá del "plan"}

Hasta aquí, hemos reconstruido las miradas, justificaciones y controversias que se recrean sobre la asistencia, los sujetos destinatarios y su relación con el trabajo, en los diferentes 
grupos de discusión analizados. Los discursos sobre el merecimiento suponen diferentes visiones acerca del "deber ser" de la política social y del rol del Estado en relación con las problemáticas vinculadas al trabajo. Asimismo, ponen en juego modos de explicar las situaciones de "no trabajo" y de pobreza que afectan a un sector de la sociedad. Dichas redes de causas son fundamentales en los juicios expresados sobre la conveniencia, efectividad y justicia de las intervenciones asistenciales. Finalmente, los discursos relevados ofrecen perspectivas de las condiciones y atributos morales para “merecer" de forma legítima la ayuda estatal.

Hemos destacado el fuerte cuestionamiento hacia los llamados "planes sociales" que se expresa en el abordaje de la política social y, en particular, del tema de las transferencias monetarias.Asimismo, observamos la particularización de la población destinaria de las transferencias de ingresos como un otro social y moralmente distinto, en el marco de una explicación del desempleo como un problema eminentemente individual. Estos argumentos se enlazaban, en ocasiones, con una crítica radical hacia los "planes sociales" por promover efectos negativos en quienes los reciben y para el conjunto de la sociedad, asociados al abandono de la cultura del trabajo. Sin embargo, también observamos resistencias y lecturas alternativas a esta mirada sobre la sociabilidad y el mundo del trabajo, cuyo foco está colocado en el problema de "los desocupados", "los pobres" o "los que cobran planes". Estas otras formas de percepción se basan en una explicación diferente del problema, en la que emergen factores estructurales y colectivos sobre las situaciones de "no trabajo”. Además, colocan en el registro del trabajo (no en la asistencia) las alternativas y soluciones genuinas.

Señalamos que, pese a que estos discursos aparecen como contrapuestos, en los grupos de discusión no se presentan como formaciones polares y excluyentes. En este orden, identificamos ciertas convergencias en base a las que estos eran ensamblados. Una de las más centrales es el consenso general sobre un horizonte deseable que en términos ideales sería que los "planes sociales" dejaran de existir, dado que no constituyen soluciones de raíz al problema del desempleo. Tampoco reemplazan el valor social del trabajo, ni garantizan la seguridad, la protección y las garantías que éste ofrece. El trabajo constituye el horizonte deseable de la participación en la vida social, tanto para sí como para otros. ${ }^{18}$ Sin embargo, la perspectiva de su eliminación no resulta sostenible para ningún participante, en ninguno de los grupos analizados. La imposibilidad de desplazar una política de corte asistencial que, pese a los matices muy diversos que hemos mostrado, no es plenamente valorada, plantea -sino una paradoja- la pregunta acerca de las alternativas disponibles socialmente para reconocer la utilidad social de los sujetos desplazados del ámbito laboral y afirmar su pertenencia legítima a la colectividad.

En este orden, el acceso a oportunidades de trabajo se vislumbra, en ciertos tramos de las discusiones, como un asunto de responsabilidad colectiva. Sin embargo la apelación a la política laboral para atender la situación de los grupos sociales afectados estructuralmente por problemas de empleo, no alcanza más que un sentido genérico. En cambio, 
la responsabilidad individual para hacer frente a las situaciones de dificultad o aprovechar las oportunidades que se ofrecen, tiene un peso muy importante para todos los participantes. En esta trama de sentidos se enmarca la mirada crítica hacia la figura de aquellos que, percibiendo planes, no realizan las contraprestaciones o no cumplen con las condiciones exigidas, o bien no ponen algo de sí ante lo que se les ofrece.

Dada la percepción de que los "planes" son, en algún punto, imposibles de erradicar pero que se despliegan múltiples problemas en sus usos, las alternativas esbozadas proponen una serie de arreglos institucionales dirigidos a controlar y promover comportamientos individuales adecuados por parte de los agentes implicados en las políticas sociales. Se valora especialmente la voluntad de capacitarse, de estudiar, o de realizar trabajo en sentido genérico, asociados a la retórica del esfuerzo. Adquiere tenor una figura clásica conformada por los sujetos dependientes que deben ser sostenidos socialmente, aunque se encuentran en condiciones de trabajar. Dicha figura constituye una alteridad completa, pues incluso los/as titulares de programas orientados a la promoción de la economía social se desmarcan de ella, señalando que esos sujetos no han aprovechado las oportunidades brindadas para capacitarse y contar con mayor autonomía económica y poder de decisión sobre sus vidas. Como plantea Agnes Heller (1994), es la consideración del otro como parte de una categoría social común la que habilita el tratamiento como iguales y no la existencia de reglas o normas abstractas, las que sancionarían esta posibilidad. La cualificación moral de los asistidos como un otro privado de valor social (Elías 2003) por su desenganche duradero respecto del mercado laboral precede al estigma que la categoría de "plan social" cristaliza sobre ellos.

El trabajo resulta, en todos los casos, definitorio del reconocimiento social y cultural de sujetos y grupos, es el soporte de la construcción de identidades y de la pertenencia legítima a la sociedad y el acceso a las protecciones sociales. A pesar de ello, frente a los problemas estructurales del mundo del trabajo, las alternativas "al plan" apelan fundamentalmente a incrementar el control sobre los destinatarios para reforzar la responsabilidad individual orientada a "devolver" el recurso o la oportunidad que la sociedad le está brindando. La fuerte asociación entre "planes" y política social que atraviesa los debates en los grupos focales realizados, da cuenta de la gravitación de la lectura neoliberal de la sociedad como una agregación serial de individuos, que diluye el reconocimiento de los soportes sociales y político-instituciones en los que se funda la autovalía de los sujetos. Muestra también los límites de la crítica social para plantear alternativas que los trasciendan y expresa la perdurabilidad de los sentidos construidos por el proyecto neoliberal en nuestro país sobre la experiencia de sociabilidad vinculada con esta forma de intervención social del Estado.

El mérito y el esfuerzo se revelan en los debates que reconstruimos como valores esenciales en la construcción de un nosotros. Por eso, las demandas de reconocimiento social que expresan los participantes desde las diversas posiciones sociales en las que 
se inscriben, interrogan permanentemente la medida en que el esfuerzo realizado es valorado socialmente, así como el aporte que otros realizan a la sociedad (Dubet 2017). Estas demandas se sostienen en el ideal de la igualdad de oportunidades, cuyo fracaso se constata en la realidad, y que vislumbra un horizonte de competencia equitativa que trasciende al ámbito propiamente mercantil para extenderse hacia múltiples esferas de la vida social (Dubet 2011; Dardot y Laval 2013). En este punto, las expectativas sobre la integración social y la vida en común resultan sumamente alteradas.

Todo ello nos exige pensar el neoliberalismo no sólo como un conjunto de políticas sino como un "régimen de existencia de lo social" (Gago 2015:9), como un proyecto político-cultural que entraña formas de expresión y percepción del mundo. Tal como se evidenció en los grupos analizados, las interpretaciones neoliberales sobre las políticas sociales y el desempleo son puestas en cuestión, en muchos casos por sujetos que participaron de formas cooperativas de organización del trabajo. Estos cuestionamientos, no obstante, no se presentan de forma compacta y recurren a fundamentos diversos.

Quedan abiertas, entonces, algunas interrogantes y desafios para pensar la política social en el nuevo contexto de reconstrucción neoliberal. ¿Cómo superar los límites de la crítica social a la asistencia al desempleo para construir formas alternativas de integración y sociabilidad? ¿Cómo abordar la tensión entre responsabilidad colectiva y responsabilidad individual y cuáles son las posibilidades y límites de la intervención estatal en este camino? 


\begin{abstract}
${ }^{1}$ Proyecto "Autovalía y dependencia legítima. La política social y los soportes socio-institucionales de la vida social”. Universidad de Buenos Aires- Secretaría de Ciencia y Técnica (2014-2017), dirigido por Estela Grassi y proyecto PIO CONICET UNGS (2015-2016) No 144-20140100006-CO “Los fundamentos socio-político y culturales de la protección social: alcances y legitimidad de los sistemas institucionales 2003-2016”, dirigido por Susana Hintze.

${ }^{2}$ Cabe señalar que la dimensión institucional no es solo formal o normativa, pues allí también se ponen en juego las prácticas específicas de los agentes estatales que se despliegan en la escala cotidiana de la política que pueden habilitar o restringir el acceso a las mismas, así como construir diversos sentidos de la intervención
\end{abstract} estatal y de esa relación con los/as destinatarios/as (Grassi, 2014).

${ }^{3} \mathrm{Al}$ respecto, Castel (1997) señala que el merecimiento a la asistencia históricamente estuvo sometido a una contradicción insoluble, cristalizada en la figura del "mendigo válido". Dicha tensión se vincula con la necesidad de sostener a aquellos que no trabajan porque el mercado laboral no precisa de sus capacidades, tensión que se agudiza en nuestros días.

${ }^{4}$ El Plan de Inclusión Previsional implementado por la Administración Nacional de la Seguridad Social (ANSES) en el año 2005, y su segunda etapa en 2014, buscaron garantizar el acceso a la jubilación a las personas que contaran con la edad pero no los años de aportes necesarios para jubilarse, a través de un plan de regularización de los aportes faltantes, conocido como moratoria previsional. A esta moratoria, se sumó una ampliación sin precedentes de la cobertura de las pensiones no contributivas (Lombardía y Rodríguez, 2015; Calvi y Cimillo, 2013). Asimismo, hasta el año 2009 se decretaron aumentos sucesivos del haber mínimo que posteriormente se generalizaron para todas las categorías con la Ley de Movilidad Jubilatoria.

${ }^{5}$ En 2011 se implementó la Asignación por Embarazo para Protección Social destinada a mujeres embarazadas en las mismas condiciones de acceso a la Asignación Universal.

${ }^{6}$ Inicialmente esto se realizó mediante el otorgamiento de subsidios destinados a grupos familiares y asociativos para la compra de herramientas e insumos de trabajo, mediante el Plan Nacional de Desarrollo Local y Economía Social “Manos a la Obra”. En un segundo momento, entre 2009 y 2015, este Plan se reconfiguró dándole centralidad a la creación de cooperativas de trabajo mediante los Programas Ingreso Social con Trabajo “Argentina Trabaja” y su ampliación en 2013, de la línea "Ellas Hacen”, destinada a mujeres con hijos en situación de alta vulnerabilidad social o víctimas de violencia de género (Hopp, 2017b).

${ }^{7}$ De hecho las transferencias monetarias se mantuvieron o se ampliaron con el fundamento de una pretendida búsqueda de igualdad de oportunidades o de la necesidad de "ayudar" a los que más lo necesitan. Por ejemplo, en abril de 2016 se extendió el acceso a las asignaciones familiares para trabajadores en relación de dependencia a los monotributistas, cuyo efecto fue el ingreso de casi 220.000 niños al sistema. También se aumentaron los topes de ingreso familiar para el cobro de estas asignaciones. Recuperado de http://noticias.anses.gob.ar/noticia/mas-deun-millon-de-ninos-se-sumaron-al-cobro-de-las-asignaciones-familiares-en-abril-1724 Asimismo, se otorgaron aumentos a los programas Argentina Trabaja y Ellas Hacen y pagos extraordinarios de fin de año para los titulares de programas y prestaciones sociales. La excepción a esta ampliación fueron las pensiones no contributivas que de acuerdo a información de prensa, el nuevo gobierno suspendió y eliminó alrededor de 173 mil pensiones por invalidez (Carrillo, 2017. Página 12, 23/6/2017. Recuperado el 18 de agosto de 2017 de https://www. pagina12.com.ar/45809-cambiemos-una-menor-cobertura-social-por-ahorro-fiscal). Esta situación generó un fuerte reclamo de la sociedad civil y distintas organizaciones sociales que lograron la revisión de los casos de pensiones por discapacidad y la supuesta restitución de las mismas. Sin embargo, al momento de publicación de este artículo, no existían datos oficiales que dieran cuenta de la magnitud de bajas y reincorporaciones.

${ }^{8}$ La Pensión Universal para el Adulto Mayor fue creada mediante la ley 27.260. Está destinada a personas de 65 años de edad o más que no cuenten con otras prestaciones de la seguridad social, jubilación, pensión o retiro. El monto de la misma equivale a un $80 \%$ de la jubilación mínima.

${ }^{9}$ Por ello fue materia de análisis indagar en qué medida estas segmentaciones ordenan (o no) la repartición de los núcleos de significatividad identificados, los consensos y las controversias.

${ }^{10}$ Se atendió a una conformación mixta entre la Ciudad Autónoma y el Gran Buenos Aires, entre varones y mujeres, y entre distintas franjas de edad.

${ }^{11}$ La única excepción fue el grupo de obreros y trabajadores autónomos informales, debido a la centralidad que asignamos a ambas categorías en cuanto a los efectos en estos segmentos de las políticas socio-laborales implementadas durante el ciclo 2003- 2015.

${ }^{12}$ La relevancia y el interés de considerar el sector del trabajo cooperativo se vincula, por un lado, con la necesidad de producir información sobre formas de trabajo menos estudiadas y que fueron impulsadas activamente desde la política pública como estrategia de abordaje de los problemas del desempleo y la pobreza, especialmente desde el año 2003. Se trata de experiencias desarrolladas desde distintos sectores sociales pero que aún no cuentan con categorías que las capten en las estadísticas oficiales, ni con formas de protección social adecuadas. Por otro, porque pueden constituirse en un contrapunto en tanto se trata de prácticas de trabajo no asalariadas que buscan poner en juego otras formas de relación social y laboral. 
${ }^{13}$ En lo que sigue, los extractos de los grupos de discusión se acompañan de la referencia de las categorías ocupacionales del grupo que se trate. Para resguardar el anonimato de los/as participantes, se utilizan iniciales para referenciar los diálogos. La letra "E" remite a la entrevistadora. En ciertos casos hemos indicado ocupación y género de los/as participantes, en función de su relevancia para el análisis. Finalmente, las cursivas en los diálogos funcionan como resaltados propios de las autoras.

${ }^{14}$ Chaves, Fuentes y Vecino (2017) analizan la experiencia de jóvenes de sectores populares e indagan los modos en que se construyen fronteras y lógicas de merecimiento, a través de un discurso meritocrático que justifica y legitima la desigualdad. Remitimos a la obra completa para el análisis de las diversas retóricas asociadas al esfuerzo como núcleo organizador de las diferencias sociales.

${ }^{15}$ Extraído del Grupo 3 de Obreros y trabajadores/as informales.

${ }^{16} \mathrm{Al}$ momento de la realización de los grupos focales (septiembre-octubre de 2016) el valor el Salario Mínimo,Vital y Móvil era de 7.560 pesos.

${ }^{17}$ En junio de 2016, la vicepresidenta de la Nación, Gabriela Michetti, se refirió a la situación económica del país a partir de la metáfora de un túnel del cual se saldría lentamente, en el futuro. La "explicación" de la estrategia del gobierno nacional para resolver los problemas económicos, se popularizó y difundió en distintos medios de comunicación, siendo blanco de duras críticas. Diario Clarín (5/6/2016) Michetti: "En el segundo semestre aparece la luz allá lejos, pero seguís en el túnel” https://www.clarin.com/politica/michettisegundo-semestre-aparece-seguis_0_EJh7dzpm-.html

${ }^{18}$ Esto se cristaliza en las distintas formulaciones de los participantes: "No te tienen que dar plata sino la posibilidad de trabajo" (trabajadores/as rutinarios/as) o "Está perfecto, que eliminen los planes pero que generen trabajo, que abran industrias" (cooperativistas y destinatarios/as Argentina Trabaja y Ellas hacen), entre otras. 


\section{Referencias bibliográficas}

Calvi, Gabriel. y Cimillo, Elsa (2013) “Transferencias estatales y distribución personal del ingreso en la Argentina reciente”. Voces en el Fénix, 22, 52-61. Recuperado de: http:// www.vocesenelfenix.com/content/transferencias-estatales-y-distribuci\%C3\%B3npersonal-del-ingreso-en-la-argentina-reciente

Castaño Zapata, Daniel (2015) “¿Merecer o no merecer? Un análisis estructural de la cuestión”.VI Encuentro Regional de Estudios del Trabajo Crisis capitalista y situación del trabajo y los/as trabajadores/as. Universidad Nacional del Centro de la Provincia de Buenos Aires, Buenos Aires. Recuperado de: http://proieps.fch.unicen. edu.ar/cds/2015/pdf/mesa5/castanozapatadaniel.pdf

Castel, Robert (1997) Las metamorfosis de la cuestión social. Una crónica del salariado. Buenos Aires: Paidós.

Chaves, Mariana; Fuentes, Sebastián y Vecino, Luisa (2017) Experiencias juveniles de la desigualdad. Fronteras y merecimientos en sectores populares, medios altos y altos. Buenos Aires: Grupo Editor Universitario-CLACSO.

Danani, Claudia (2004) Política Social y Economía Social: debates fundamentales. Buenos Aires: Altamira.

Danani, Claudia y Estela Grassi (2008) “Ni error, ni omisión. El papel de la política de Estado en la producción de las condiciones de vida y de trabajo. El caso del sistema previsional en la Argentina (1993-2008)". En J. Lindemboim (comp.) Trabajo, ingresos y políticas en Argentina. Contribuciones para pensar el siglo XXI. Buenos Aires:Eudeba,259-298

Danani, Claudia (2017) "Políticas sociales universales: una buena idea sin sujeto. Consideraciones sobre la pobreza y las políticas sociales”. Revista Sociedad, 37, 77-94.

Danani, Claudia y Javier Lindenboim (2003) “Trabajo, política y políticas sociales en los 90: ¿hay algo de particular en el caso argentino?”. En J. Lindenboim y C. Danani (coord.) Entre el trabajo y la política. Las reformas de las politicas sociales argentinas en perspectiva comparada. Buenos Aires: Biblos, pp. 253-266.

Dardot, Pierre y Christian Laval (2013) La nueva razón del mundo. Ensayo sobre la sociedad neoliberal. Barcelona: Gedisa.

Dubet, François (2017) Lo que nos une. Cómo vivir juntos a partir de un reconocimiento positivo de la diferencia. Buenos Aires: Siglo XXI Editores. 
Elías, Norbert (2003) "Ensayo acerca de la relación entre establecidos y forasteros". Reis, 104, 219-251.

Gago, Verónica (2015) La razón neoliberal: economías barrocas y pragmática popular. Buenos Aires: Tinta y Limón.

Grassi, Estela; Susana Hintze y María Rosa Neufeld (1994) Políticas sociales, crisis $y$ ajuste estructural. Buenos Aires: Espacio Editorial.

Grassi, Estela (2003) Políticas y Problemas sociales en la sociedad neoliberal. La otra década infame (I). Buenos Aires: Espacio Editorial.

Grassi, Estela (2004) Política y Cultura en la sociedad neoliberal. La otra década infame (II). Buenos Aires: Espacio Editorial.

Grassi, Estela (2012) "La política social y el trabajo en la Argentina contemporánea. Entre la novedad y la tradición”.E-1@tina Revista electrónica de estudios latinoamericanos, 10(39), 5-33.

Grassi, Estela (2014) "Regímenes universalistas, derechos e igualdad. La escala cotidiana de las políticas sociales”. En: A. Arias (coord.) Debates en torno a la construcción de institucionalidad. Buenos Aires: Espacio Editorial, pp. 51-56.

Heller, Agnes (1994) Más allá de la justicia. Barcelona: Planeta - Agostini.

Hintze, Susana (2007) Políticas sociales argentinas en el cambio de siglo. Conjeturas sobre lo posible. Buenos Aires: Espacio Editorial.

Hopp, Malena (2017a) “Transformaciones en las políticas sociales de promoción de la economía social y del trabajo en la economía popular en la Argentina actual”. Cartografías del Sur, 6, 19-41.

Hopp, Malena (2017b) "Políticas de promoción de la economía social en Argentina: desafios para la construcción de una nueva institucionalidad”. En: J. L. Coraggio (ed.) Miradas sobre la economía social y solidaria en América Latina. Buenos Aires: IAEN-UNGS, pp. 19-62.

Lombardía, María Laura y Rodríguez, Karina. (2015) “La experiencia argentina en políticas de transferencias monetarias durante la última década". Documento de Trabajo N7. Secretaría de Política Económica y Planificación del Desarrollo. Recuperado de: http:// www.economia.gob.ar/peconomica/basehome/DT_07\%20la\%20experiencia_03.pdf

Merklen, Denis (2005) Pobres ciudadanos. Las clases populares en la era democrática (Argentina, 1983-2003). Buenos Aires: Gorla. 
Morell, Antonio (2002) La legitimación social de la pobreza. Barcelona:Antrophos Editorial.

Paugam, Serge (2007) Las formas elementales de la pobreza. Madrid: Alianza.

Schmidtz, David (2000)“Asumir la responsabilidad”.En D. Schmidtz y R. E. Goodin. El Bienestar y la Responsabilidad Individual. A favor y en Contra. Cambridge: Cambridge UniversityPress, pp. 23-114.

Soldano, Daniela y Luciano Andrenacci (2005) “Aproximación a las teorías de la política social a partir del caso argentino". En L.Andrenacci (comp.) Problemas de política social en la Argentina contemporánea. Buenos Aires: Prometeo, pp. 17-80.

Scribano, Adrián y Vanina Fraire (2008) “El grupo de discusión: posibilidades y estrategias”. En A. Scribano. El proceso de investigación social cualitativo. Buenos Aires: Prometeo.

\section{Fuentes}

Administración Nacional de la Seguridad Social (2015) Libro Blanco de Gestión,ANSES.

ANSES. Recuperado de http://noticias.anses.gob.ar/noticia/mas-de-un-millon-deninos-se-sumaron-al-cobro-de-las-asignaciones-familiares-en-abril-1724

Casa Rosada (16/4/2016) Recuperado de http://www.casarosada.gob.ar/ slider-principal/36022-el-presidente-macri-anuncio-un-paquete-de-medidas-sociales

CESO - Centro de Estudios Scalabrini Ortiz (2016) Informe económico mensual, enero 2016.

Recuperado de: http://www.ceso.com.ar/informe-economico-mensual-enero-2016

Decreto del Poder Ejecutivo Nacional 1602 de 2009.

Diario Clarín (5/6/2016) Michetti:“En el segundo semestre aparece la luz allá lejos, pero seguís en el túnel” https://www.clarin.com/politica/michetti-segundo-semestre-aparece-seguis_0_EJh7dzpm-.html; https://www.youtube.com/watch?v=Kc5Gy0Vf43c

Ley 27.345

Ley 27.260

Página 12 (23/6/2017). Recuperado el 18 de agosto de 2017 de https://www.pagina12.com.ar/45809-cambiemos-una-menor-cobertura-social-por-ahorro-fiscal 
Resolución Ministerio de Desarrollo Social 456 de 2016.

Resolución Ministerio de Desarrollo Social 592 de 2016.

Resolución Ministerio de Desarrollo Social 2055 de 2016.

\section{Cómo citar este artículo:}

Malena Victoria Hopp y Eliana Lijterman (2018) “Trabajo, políticas sociales y sujetos "merecedores" de la asistencia: acuerdos y debates en el nuevo contexto neoliberal en Argentina". Revista Perspectivas de Políticas Públicas vol. 8 N¹5: 139-171 